\title{
The Pattern of In Situ Stress in Onshore Basins of New South Wales
}

\author{
Mojtaba Rajabi ${ }^{1}$, Mark Tingay ${ }^{1}$, Oliver Heidbach ${ }^{2}$ and Rosalind C. King ${ }^{3}$ \\ ${ }^{1}$ Australian School of Petroleum, The Univerity of Adelaide, Adelaide, SA, Australia. \\ ${ }^{2}$ Section 2.6 Seismic Hazard and Stress Field, GFZ German Research Centre for Geosciences, Potsdam, Germany. \\ ${ }^{3}$ School of Earth and Environmental Sciences, The Univerity of Adelaide, Adelaide, SA, Australia. \\ September 15, 2015 Tuesday 10:00 A.M. International Conference \& Exhibition, Melbourne, Australia
}

\begin{abstract}
The in-situ stress field has numerous applications in different earth science disciplines including, geodynamics, intraplate deformation, seismic hazard assessment, mine safety and geomechanical characterization of hydrocarbon/geothermal reservoirs. New South Wales (NSW), Australia, contains large coal seam gas reserves in different sedimentary basins. In addition, southeast of NSW, along with Victoria, is one the most active seismic regions of Australia (i.e. South-East seismic zone). Despite the numerous potential sources of stress data, only 95 maximum horizontal stress (SHmax) orientation measurements for NSW were available in the World Stress Map database prior to this study, mostly from shallow engineering measurements. Coal seam gas exploration in several basins of NSW, including the Gunnedah, Clarence-Moreton, Sydney, Gloucester and Bowen-Surat basins, provide the opportunity to investigate the SHmax pattern in this poorly resolved part of the continent. We compiled 236 (A-E quality) horizontal stress orientations from different part of NSW and present the first detailed stress map of NSW within six stress provinces. The database contains 331 (including 318 A-D and 13 E quality) SHmax orientations consisting of 186 stress indicators from borehole breakouts, 69 stress measurements from shallow engineering methods, 46 stress indicator from drilling induced fractures and 30 stress indicators from earthquakes. SHmax in the Clarence Moreton Basin is approximately E-W; in the Gunnedah, Bowen and Surat is NE-SW; is generally ENE-WSW in the Sydney Basin; and has a variable pattern in the Gloucester Basin. Herein, we compare the observed stress pattern with the previous plate scale models and show none of the models could predict the stress pattern. We also show several examples of stress rotation (spatially and in a single well) due to different geological parameters particularly faults, fractures and intrusion of volcanics into sediments, which particularly is important for exploration and production of coal seam gas \& shale gas reservoirs and can significantly affect stimulations. Hence, it may not be appropriate to base fracture design on the SHmax orientation observed from just a few wells in a basin or field. Rather, it is important to undertake detailed analysis of SHmax orientation from all available data to adequately constrain the regional and local-scale perturbations in the stress field.
\end{abstract}

AAPG Datapages/Search and Discovery Article \#90217 @ 2015 International Conference \& Exhibition, Melbourne, Australia, September 13-16, 2015 
